\title{
Paradigms for Mechanical Signal Transduction in the Intestinal Epithelium
}

\author{
Category: Molecular, Cell, and Developmental Biology
}

\author{
Marc D. Basson
}

Departments of Surgery, Wayne State University and John D. Dingell VA Medical Center, Detroit, Mich., USA

\section{Key Words}

Physical forces - Caco- 2 cells · Intestinal mucosa, mechanical and physical forces · Small intestine, rat · Villous motility · Intestinal mucosa during normal gut function · Intestinal epithelial proliferation · Signaling pathways - Mechanical force effects upon epithelium

\begin{abstract}
Diverse physical forces including deformation or strain, pressure, and shear stress affect the intestinal mucosa during normal function, and mucosal biology is altered in pathological states in which these forces alter. Taken together with evidence in other tissues and cell types that physical forces can affect cell biology, this has led to the hypothesis that repetitively applied physical forces can initiate intracellular signals that alter intestinal epithelial proliferation and phenotype. This review outlines the nature of such forces and summarizes in vivo and in vitro evidence in support of the paradigm that repetitive force is trophic for the intestinal mucosa via a complex cascade of intracellular signals.
\end{abstract}

Copyright $@ 2004$ S. Karger AG, Basel

\section{Introduction}

Although much is known about the regulation of intestinal epithelial biology, there is still a great deal that remains unexplained. For instance, despite all of the work that has been done on the subject, we still do not fully understand why mucosal atrophy occurs in patients who are receiving adequate parenteral nutrition but nothing by mouth. (It is almost a truism that luminal nutrition is the key to mucosal preservation, but why should that be? Granted, various nutrient transport mechanisms may be distributed in a polarized fashion in the intestinal epithelial cell, but diffusion does occur, and it seems at least theoretically that it should be possible to provide nutrients to an intestinal epithelial cell via the parenteral route.) This review is intended to summarize evidence from our laboratory and others that mechanical forces acting on the gut mucosa may activate specific signaling pathways that may alter gut mucosal biology. Although such signals must certainly interact with signals generated by other more conventional biologic agents such as growth factors, hormones, nutrients, and extracellular matrix proteins, it seems likely that a more complete understanding of intestinal mucosal physiology and pathophysiology will be achieved if the effects of mechanical forces are also understood and taken into account.

Dr. Marc Basson, Chief, Surgical Service

John D. Dingell VA Medical Center

4646 John R. Street

Detroit, MI 48201-1932 (USA)

E-Mail karger@karger.ch_Accessible online at:

www.karger.com www.karger.com/dig
Tel. +1 313576 3598, Fax +1 313576 1002, E-Mail marc.basson@med.va.gov 
Table 1. Factors generating force upon the intestinal mucosa

\begin{tabular}{ll}
\hline During normal function & During disease \\
\hline Tonic strain & Starvation \\
Peristalsis & Malnutrition \\
Feeding & Ileus \\
Physical interactions with luminal contents & Bowel obstruction \\
Nutrient absorption & Inflammation \\
Mucosal remodeling & Ulceration \\
$\begin{array}{l}\text { Cell shape changes and movement } \\
\quad \text { during restitution }\end{array}$ & Edema \\
\hline
\end{tabular}

Although neural mechanosensing in the gut via vagal afferent mechanoreceptors is well described [e.g., see 1], this subject will not be discussed in the present review, which focuses on the issue of mechanical force effects upon the epithelium.

\section{Physical Forces Acting upon the Intestinal Mucosa during Normal Gut Function}

The intestinal mucosa is subjected to a wide variety of physical forces during normal function and in pathophysiologic states. These include deformation, pressure and shear stress engendered by villous motility, peristalsis, interaction with luminal contents, and mucosal remodeling and healing (table 1). Increasing evidence suggests that such forces may trigger signals within intestinal epithelial cells that alter intestinal epithelial biology (fig. 1). Although each of these might itself merit a comprehensive essay, the following represents a brief overview of these forces to provide the background that motivates research into the effects of mechanical forces on gut mucosal biology.

\section{Tonic Strain}

Under normal in vivo conditions, the bowel wall is subject to constant strain, determined by its histology, shape and mechanical properties, as well as tonic muscular contraction. This strain varies in a complex fashion between layers of the gut, as well as along the gradient from duodenum to colon [2, 3]. Mucosal compressive residual strain in excised rat small intestine in organ baths has been estimated at $25-40 \%$ [2]. Interestingly, this tonic strain may be altered by conditions as diverse as growth factors, radiation, diabetes, or fasting [4-7].

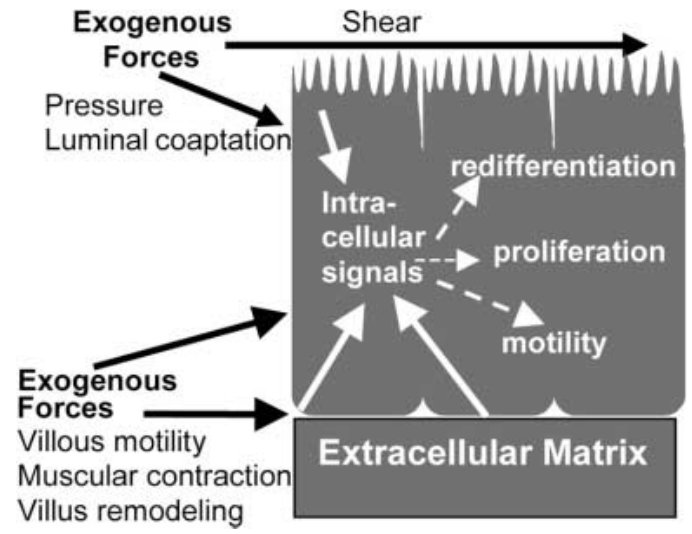

Fig. 1. Diverse physical forces, engendered by the bowel itself and by the luminal contents of the intestine, act upon intestinal epithelial cells. Such forces are likely to trigger a complex cascade of intracellular signals that regulates intestinal epithelial proliferation and phenotype.

\section{Villous Motility}

Spontaneous repetitive intestinal villus contraction, first described in 1843 , is a process by which intestinal villi (including the overlying mucosa) repetitively lengthen and shorten dramatically. Villus motility is mediated by smooth muscle fibers from the muscularis mucosa oriented along the villus, and has more recently been extensively and rigorously characterized by Womack. Individual villi contract $0-15$ times $/ \mathrm{min}$, at a frequency that decreases along the gradient from the duodenum to the terminal ileum [8]. Although villar shortening during contraction has not been measured, published videomicroscopic images [9] suggest a dramatic decrease. The frequency of villous motility is also regulated by input by neurohumoral and luminal factors. Exposure of the villi to amino acids or fatty acids increases contractile frequency by $30-50$ and $90 \%$ respectively [8]. Water absorption and vagal stimulation also correlate with increased villus motility, while vagotomy and sympathetic stimulation inhibit it $[9,10]$. Bile salts modulate the lipid effects [11].

\section{Peristalsis}

The patterns of small and large bowel peristalsis are complex and vary with feeding and fasting. For instance, in fasting, cyclic migrating motor complexes sweep down the small bowel every 90-120 min, producing a complex four-phase contractile pattern. Such other deformations as giant migrating contractions also occur. The fasting 
motility pattern is disrupted in the fed state, when it is replaced by a more complex combination of irregular and intermittent contractions that mix the luminal contents and slow its aborad progression. In addition to the strain caused by these contractions in the fed state, propulsive activity against luminal contents may also increase intraluminal pressure while the proximal bowel contracts and the distal bowel relaxes in a peristaltic reflex. Numerous excellent reviews exist on the gut motility $[12,13]$, which exceeds the scope of the current essay, and considerable effort has been directed at mathematical modeling of this process $[14,15]$. Gut peristalsis reflects contraction of the circular and longitudinal muscular layers of the bowel. However, endoscopic or fluoroscopic observation readily demonstrates alterations in the gut lumen shape during muscular contractions. Longitudinal smooth muscle may induce mucosal strain since fluoroscopy shows that small bowel segments themselves move and bend within the abdomen, and this may induce strain on the mucosa. However, biomechanical models of intestinal contractility suggest that changes in luminal and mucosal configuration originate primarily from contraction of the circular smooth muscle and that these contractile forces are likely to be transmitted across the mucosa to luminal contents. Since luminal contents are largely non-compressible, this would increase pressure on the mucosa and change intestinal epithelial shape [14-16].

We recently measured the \% deviation from average luminal diameter over $30 \mathrm{~s}$ at 0.5 -s intervals at 5 random points in the small bowel in 5 patients who had normal small bowel follow-throughs after UGI series, and (assuming a round lumen $[14,15])$ calculated an average deformation over this time interval for each of these 25 series. Our results ranged from 7.2 to $27.4 \%$. Such measurements involve multiple assumptions and cannot be considered to yield precisely accurate results. However, they do suggest that the mucosa lining the lumen does deform in vivo and that the $10 \%$ strain used for recent in vitro studies of the effects of strain on the gut epithelium is within the range of mucosal deformation in vivo. Indeed, measurements of rat colon suggest that it is prestrained to $10 \%$ and capable of strain in excess of 200\% [17].

Even without quantitative models, it is readily apparent that repetitive bowel contraction must lead to the application of multiple and complex forces on intestinal epithelial cells. These are likely to include deformation or strain during mucosal stretching, and pressure and shear stress when mucosal surfaces actually rub together. Indeed, McNeil and Ito [18] have described repetitive mucosal epithelial injuries that appear to be caused by either mucosal apposition or contact with luminal contents during normal gut function.

\section{Mechanical Effects of Luminal Contents}

Indeed, intestinal contractile activity alters not only intestinal mucosal strain but also pressure on the mucosa, as smooth muscle contractions within the bowel wall compress the mucosa against generally non-compressible or minimally compressible bowel contents $[19,20]$. Within the colon, of course, the most extreme evidence of deformation of the mucosa pressure may be the formation of diverticulae, which have been widely ascribed to constipation and increased colonic intraluminal pressure [21, 22]. Fiber supplementation is associated with decreased colonic luminal pressures in rats [23], monkeys [24] and humans [25,26], and this may be one of the mechanisms by which fiber decreases morbidity from diverticular disease [27]. In addition to participating in generating pressure on the mucosa, the luminal contents also induce other forces on the mucosa, including shear stress and further villus deformation during frictional passage along the bowel wall, and deformation of the bowel when a particularly large bolus of material passes.

\section{Effects of Nutrient Absorption and Adaptation}

Luminal nutrients can themselves rapidly alter peristaltic amplitudes, frequencies, and rhythms [12, 13]. Fiber supplementation may also alter colonic peristaltic patterns [28]. However, the presence of specific nutrients in the gut lumen can have other effects on the morphology of the mucosa. Further epithelial deformation occurs when the apical membrane is converted to endosomal membrane during lipid absorption [29] or when broadening or fusion of the villi occurs during ingestion of fiber [30]. Deformation also occurs when villus height increases in lactation [31, 32] and after small bowel resection [33, 34]. Conversely, radiation injury decreases villus height, an effect partially reversed by atropine [35].

\section{Physical Forces Acting upon the Intestinal Mucosa during Gut Pathology}

\section{Effects of Starvation or Prolonged Fasting}

Prolonged fasting or starvation has several effects that may modulate the physical forces acting on the gut mucosa. First, and most obviously, the intermittent switch to postprandial motility patterns is lost, along with changes in volume, density, and composition of the luminal contents. Second, the mucosa itself becomes atrophic, with 
shortened villi in the small bowel mucosa [36]. Such a shape change may alter the direction and force when exogenous physical stimuli are applied to the gut mucosa in addition to itself deforming the mucosa slowly over time. Third, in states of malnutrition, as serum albumin and other proteins decrease, plasma colloid osmotic pressure is also decreased, and tissue edema occurs. Mucosal edema can typically be seen radiologically if the serum albumin falls below 2 [37], but is likely to occur even at less decreased albumin concentrations, since radiologic evaluation of mucosal edema is likely to be relatively insensitive.

\section{Effects of Ileus}

Intestinal ileus, whether postoperative or related to disease states, is characterized by loss of the fasting motility pattern. Peristaltic contractions may be decreased or absent $[38,39]$. Although the subject has not been investigated, villous motility also seems likely to be altered because of derangements in its neurohumoral control mechanisms. In chronic ileus, the bowel may also become quite edematous and/or full of liquid luminal contents that may cause static distension and altered luminal pressures despite the loss of bowel contraction.

\section{Effects of Edema, Inflammation or Ulceration, and Obstruction}

Like decreased oncotic pressure related to malnutrition or acute hemodilution, increased capillary pressure results in mucosal edema that may increase extracellular pressure around intestinal epithelial cells. The edematous gastric mucosa of portal gastropathy is well known to clinicians, and similar edema may occur in the intestinal mucosa. Ischemia/reperfusion injury is also associated with edema, while progressive bowel obstruction results in not only increased luminal pressures but also increased capillary pressure and edema when venous return is compromised. Inflammatory or allergic diseases also cause mucosal edema, while mucosal ulceration or breach of the mucosal barrier is itself associated with an increase in tissue pressure. The underlying pathophysiology responsible for such bowel edema has been comprehensively reviewed elsewhere [40].

\section{Effects of Cell Motility}

Mucosal injury may occur in response to gastrointestinal pathology, such as peptic ulcer disease, inflammatory bowel disease, infectious gastroenteritis or colitis, or surgical trauma. However, small mucosal wounds also occur constantly during normal gut function, perhaps because of friction with mucosal contents [18]. Such mucosal injuries result in restitution, a process by which intestinal epithelial cells adjacent to the mucosal wound flatten out, become squamous in morphology, extend lamellipodia, and migrate across the defect in order to resurface it [41, 42]. Such substantial morphologic changes are also likely to cause physical deformation of these intestinal epithelial cells. In addition, cells at the edge of the migrating epithelium exert substantial physical forces upon cells behind the wound margin during epithelial migration, pulling them across the wound in a sheet and likely deforming them as well $[43,44]$.

\section{Evidence that Mechanical Forces Alter Cell Biology in Other Cell Types}

Interest in processes as diverse as the effects of hypertension on the vasculature and loading pressures on bone remodeling has led to substantial effort directed at modeling the effects of physical forces on cells. There is now widespread in vitro evidence that mechanical forces such as repetitive deformation, pressure, and shear stress alter the cell biology of various non-intestinal cell types [45]. For instance, the effects of physical forces on endothelial cells [46], pulmonary smooth muscle cells [47], and articular chondrocytes [48] have recently been reviewed.

Although most cell types that have been investigated seem susceptible to some sort of physical force effects, it is important to note that these effects differ between cells. For instance, strain stimulates aortic endothelial cells to proliferate and synthesize $\mathrm{PGI}_{2}$ but pulmonary arterial and vena caval endothelial cells exhibit neither response [49]. In contrast, osteoblastic periodontal ligament cells exhibit decreased proliferation in response to repetitive strain [50].

Of further interest is the observation that different cell types appear to respond to very different frequencies of repetitive strain in vitro. Vascular endothelial cells seem to respond best to frequencies of 60-90 cycles per minute [46], while osteoblasts respond optimally to lower frequencies of about 6 cycles per minute [50]. Our own data suggests that intestinal epithelial cells respond optimally to frequencies in the 10-15 cycles per minute range [51]. Although the mechanism by which cells discriminate the frequencies of applied repetitive deformation is not known, such frequencies seem teleologically appropriate to the range of frequencies that such cells might normally experience in vivo. 


\section{Potential Mechanisms of Physical Force Effects}

The mechanism(s) by which cells sense and respond to physical forces are as yet unclear. Numerous possibilities have been suggested. These include a tensegrity model, in which mechanical elements within the cell, perhaps including the cytoskeleton, result in mechanical signals [45, 52] and activation of transmembrane ion channels that then change intracellular ion concentrations and modulate intracellular signals [48]. Such forces may activate focal adhesion proteins, but it is not clear whether this occurs via cytoskeletal force effects $[45,52]$ or integrinmediated signals engendered by deformation of the extracellular matrix and modulation of cell-matrix interaction [53-55]. In some cell types, nucleotides such as ATP and UTP may play an important role in mechanosensing [56, 57]. Since different physical forces may yield different effects, and various cell types respond to the same physical force with different consequences, it seems likely that each of these explanations may play some role in mediating the effects of some forces in some cells. Detailed mechanistic exposition must therefore focus on a single force, cell type and downstream consequence, but there would seem ample reason to suppose that intestinal epithelial cells might be able to respond to physical force via some such mechanisms.

\section{In vivo Evidence that Mechanical Forces Might Act upon GI Mucosa}

In related common bile duct epithelial cells, increased pressure from bile duct ligation increases bile duct epithelial cell proliferation [58]. Furthermore, Haussinger et al. [59] have recently described stimulation of choleresis by osmotically induced swelling in isolated perfused rat liver via integrin-dependent Src and MAPK activation that is likely to have a mechanism similar in many ways to the effects of physical forces on intestinal epithelial cells.

In the small bowel, a standardized surgical pressure decreases diamine oxidase expression (a brush border enzyme) and increases mucosal mass [60]. Mucosal atrophy in defunctionalized Thery-Vella loops is reversed by luminal water [61], suggesting that mechanical distention supports the mucosa. Indeed, we recently reported that gut mucosal tyrosine kinase signals are activated by repetitive distension of the ileum or colon in anesthetized rats using an isotonic electrolyte-balanced polyethylene glycol solution [62].

Mechanical Signals in Gut Epithelium
The effects of starvation or prolonged fasting upon the bowel mucosa have already been alluded to and are well known [34]. Although originally attributed to malnutrition, this mucosal atrophy is not reversed by total parenteral nutrition [36], which should supply all relevant nutritional requirements. Adaptation to small bowel resection is enhanced by enteral but not parenteral nutrition $[63,64]$. On the other hand, the mucosal atrophy observed in defunctionalized bowel of fasted or parenterally nourished animals is not completely reversed by oral feeding $[61,65,66]$, suggesting that even oral nutrition cannot fully support the mucosa unless the nutrients flow directly through the affected bowel. Fecal diversion has similar effects in the distal colon $[67,68]$, and attempts to reverse diversion proctitis by enemas of short chain fatty acids, the dominant energy source of the colonocyte, have also met with mixed results [69].

Intestinal epithelial cells normally derive most of their caloric supply from within the lumen, and most of the digestive enzymes are expressed in an apical brush microvillar border. It might therefore be postulated that these cells cannot exist without apical nutrients, and that this is why parenteral nutrition fails to support the gut. However, the enterocyte can derive nutrition luminally or by submucosal perfusion [70, 71]. Moreover, cultured intestinal epithelial cells survive quite nicely in culture if supplied with basal nutrients, and indeed appear to differentiate and proliferate more readily than if nutrients are only supplied apically [72]. It was also postulated that glutamine might be a constitutive nutritional requirement for the small bowel mucosa, since the small bowel mucosa derives most of its caloric needs from enteral glutamine under normal circumstances. However, glutamine supplementation of parenteral nutrition has only been partially successful in reversing gut mucosal atrophy in humans [36]. It therefore becomes attractive to hypothesize that the increased frequency and amplitude of physical forces acting on the gut mucosa under circumstances of enteral nutrition may be trophic for the gut mucosa.

\section{In vitro Studies of the Effects of Repetitive Deformation on Intestinal Epithelial Cells}

Our own laboratory has been interested for some time in modeling the effects of repetitive deformation on intestinal epithelial cells. Most of this work has utilized Caco$2_{\mathrm{BBE}}$ cells as a model for intestinal epithelial biology, although we have confirmed some key findings in primary human intestinal epithelial cells. Although originally de-

Digestion 2003;68:217-225 221 
rived from a colon cancer, Caco- 2 cells are highly differentiated epithelial cells that are commonly used to model intestinal epithelial biology. Caco- $2_{\mathrm{BBE}}$ cells represent a subclone originally selected for its high expression of brush border proteins and architecture [73].

Repetitive deformation has been applied in our studies using a computer-regulated vacuum applied to the bottom of flexible membranes. Cells are cultured on top of these membranes on a precoated matrix protein substrate. Microscopy and micrometry in Caco-2 cells on these membranes have demonstrated that the force applied to these cells is primarily uniaxial, that the cells remain adherent, and that cell elongation by applied strain is equivalent in magnitude to the deformation of the membrane [74].

We have chosen to study the effects of regular and readily analyzable strain rhythms rather than attempting to mimic the complex irregular strain patterns to which the gut mucosa is subjected in vivo as the summation of the forces describe above. When Caco- 2 cells on a collagen substrate are subject to repetitive deformation at an average $10 \%$ strain at a frequency of 10 cycles per minute $(3 \mathrm{~s}$ deformation alternating with 3 s relaxation), the cells subjected to strain display increased cell proliferation [74]. Thus, repetitive strain may be trophic for intestinal epithelial cells. Non-transformed human primary intestinal epithelial cells isolated from surgical specimens also increase proliferation in response to repetitive deformation [53], so this observation does not represent an artifact of a single established cell line, although we have chosen to continue to pursue mechanistic studies in the Caco-2 line for ease of access, analysis and reproducibility. Caco-2 cells subjected to repetitive strain also modulate their differentiation, displaying increased specific activity of the brush border enzyme dipeptidyl dipeptidase (DPDD) and decreased alkaline phosphatase-specific activity [74]. The effects of strain on Caco- 2 cells are both amplitude- and frequency-dependent, and synergistic with the effects of glutamine [51,74].

We have begun to elucidate some of the cellular signals that mediate these effects. Both tyrosine kinase and protein kinase $\mathrm{C}$ signals are activated by strain in Caco-2 cells, and blocking either tyrosine kinase or protein kinase C prevents the effects of strain [75, 76]. The PKC signal may involve translocation of the PKC $\alpha$ or $\zeta$ isozymes [75]. The mitogenic effects of strain require activation of the mitogen-activated protein kinases (MAPK) ERK 1 and 2, and are prevented by pharmacologic blockade of MEK1, which prevents the downstream activation of ERK 1 and 2. Interestingly, other major MAPK are also activated by strain in these cells, including p38 and jnk, but the role of these signals awaits further study. P38 blockade does not prevent the mitogenic effects of strain [77].

How mechanical deformation results in ERK activation is as yet unclear. However, we are beginning to identify some steps in the pathway. Repetitive deformation of Caco-2 cells on collagen also activates focal adhesion kinase (FAK), an important focal adhesion complex protein that associates with the cytoplasmic domains of integrins (cellular receptors for extracellular matrix proteins), resulting in the phosphorylation of the adapter protein paxillin, thus transducing integrin-associated signals. Blocking FAK by transfection of a dominant negative construct prevents MAPK activation by repetitive deformation, so FAK is upstream of ERK and the other MAPK [77]. We have gone on to demonstrate that the effects of strain are both integrin- and matrix-dependent. Strain activates neither FAK nor the MAPK if the cells are plated on a functional antibody substrate that permits cell adhesion only via integrin heterodimers containing the $\alpha 5$ integrin subunit, but deformation induces strong FAK and MAPK activation similar to that on a collagen substrate if the cells are plated on functional antibody substrates that permit adhesion via all $\beta 1$ integrin heterodimers or integrin heterodimers containing $\alpha 2$ (collagen-binding) or $\alpha 6$ (laminin-binding) [77]. Thus, deformation seems likely to affect integrin-mediated adhesive signaling, even without detaching the cells, and integrin-specific FAK activation in response to deformation leads to ERK activation downstream and increased cell proliferation.

Based on the observation that strain appears to affect intestinal epithelial cells by activating integrin-dependent signals within the focal adhesion complex, we further speculated that strain effects on intestinal epithelial cells might be matrix-dependent. Indeed, the mitogenic signals and effect of strain on intestinal epithelial cells are not observed if these cells are cultured on tissue fibronectin. Indeed, adding tissue fibronectin to a collagen matrix or adding plasma fibronectin at physiologically relevant concentrations inhibits these strain effects. This effect appears to be mediated by fibronectin interaction with integrin heterodimers containing the $\alpha 5$ or $\alpha \mathrm{v}$ integrin subunits, which are specific for fibronectin [53, 78]. Although these studies were chiefly performed in Caco-2 cells, the response of primary non-malignant human intestinal epithelial cells to repetitive deformation is also inhibited by fibronectin [53]. This is particularly interesting because plasma fibronectin is an acute phase reactant that increases substantially and deposits in the tissue matrix in many conditions of inflammation or severe illness, while 
tissue fibronectin itself varies substantially within the matrix during local inflammatory processes [79-84].

In related work, we recently evaluated some of the same signals during cell motility, since motility itself requires repetitive deformation and the generation of physical forces within the cell in order to achieve cell movement. Although many other factors might also be involved, it is noteworthy that Caco- 2 cell motility is also associated with an increased proportion of FAK phosphorylation, although after four days FAK protein is markedly decreased, resulting in a decreased amount of total phosphorylated FAK and (perhaps therefore) less phosphorylated ERK downstream of FAK [85].

\section{Other in vitro Studies}

Different cell types and different physical forces may have different effects. For instance, the application of repetitive mechanical strain to a rat gastric epithelial cell line (RGM-1) at lower strain parameters has been reported to inhibit both proliferation and cell motility across a type I collagen substrate. Immunohistochemical studies suggested that vinculin, RhoA and Rac1 were poorly expressed in the cells at the migrating front in the setting of repetitive strain, and the authors hypothesized a causative connection. The effects of matrix were not addressed in this study, and the observations were not extended to other gastric epithelial cell lines or to primary gastric epithelial cells [86].

Our own group $[87,88]$ has also reported that constant pressure, as distinct from repetitive deformation and relaxation, may also initiate tyrosine kinase signals in malignant intestinal epithelial cell lines as well as primary human colon cancer cells. In particular, both FAK and Src appear involved in mediating the effects of pressure, and an intact cytoskeleton may also be critical. These signals appear to activate colon cancer cell adhesion, although their relevance to non-malignant epithelium remains to be established. Interestingly, in contrast to the effects of repetitive deformation, the effects of pressure on Caco-2 cell adhesion are matrix-independent. Increased pressure may also stimulate malignant colonocyte proliferation [89]. The mechanism of this effect is not clear, although high pressures, on the order of $80 \mathrm{~mm} \mathrm{Hg}$, may be mitogenic via PKC or tyrosine kinase activation [90]. Pressure may also activate transcription factors and stimulate IL-6 secretion [91].

Osmotic forces engendered by the passage of hypertonic or hypotonic luminal contents are also likely to have important effects upon intestinal epithelial cells. For instance, osmotic stress induces nuclear factor- $\kappa \mathrm{B}$ activation and interleukin- 8 production in human intestinal epithelial cells [92]. It seems likely that such osmotic forces may also act at least in part via cell deformation and consequent mechanotransduction.

In addition, whole organ and in vitro studies also suggest that physical forces such as pressure or shear stress may activate serotonin secretion from gut mucosa and from human carcinoid BON cells [93-95]. Although the precise physical force involved is unclear from the models that were employed in the in vitro studies, such forces may stimulate a $\mathrm{G}$ protein-coupled receptor, initiating a signal cascade that activates Gaq and mobilizes intracellular calcium. The authors hypothesized that these cells might sense shear forces through microvillar mechanotransducing elements similar to those possessed by hair cells [93].

\section{Conclusions and Implications}

The intestinal epithelium is subjected to a complex and irregular pattern of physical forces during both normal function and disease. The in vivo observations and in vitro experiments described above strongly suggest that such physical forces are likely to have profound effects on the intestinal mucosa. The effects of such physical forces should be considered in attempts to understand intestinal epithelial biology.

\section{Acknowledgements}

Supported in part by a VA Merit Award and by NIH RO1 DK60771. 


\section{References}

1 Page AJ, Martin CM, Blackshaw LA: Vagal mechanoreceptors and chemoreceptors in mouse stomach and esophagus. J Neurophysiol 2002;87:2095-2103.

2 Zhao JB, Sha H, Zhuang FY, Gregersen H: Morphological properties and residual strain along the small intestine in rats. World J Gastroenterol 2002;8:312-317.

3 Gao C, Gregersen H: Biomechanical and morphological properties in rat large intestine. $\mathrm{J}$ Biomech 2000;33:1089-1097.

4 Zhao J, Sha H, Zhou S, Tong X, Zhuang FY, Gregersen H: Remodelling of zero-stress state of small intestine in streptozotocin-induced diabetic rats. Effect of gliclazide. Dig Liver Dis 2002;34:707-716

5 Zhao J, Yang J, Vinter-Jensen L, Zhuang F, Gregersen $\mathrm{H}$ : The morphometry and biomechanical properties of the rat small intestine after systemic treatment with epidermal growth factor. Biorheology 2002;39:719-733.

6 Gregersen H, Lundby L, Overgaard J: Early and late effects of irradiation on morphometry and residual strain of mouse rectum. Dig Dis Sci 2002;47:1472-1479.

7 Dou Y, Gregersen S, Zhao J, Zhuang F, Gregersen $\mathrm{H}$ : Morphometric and biomechanical intestinal remodeling induced by fasting in rats. Dig Dis Sci 2002;47:1158-1168.

8 Womack WA, Barrowman JA, Graham WH Benoit JN, Kvietys PR, Granger DN: Quantitative assessment of villous motility. Am J Physiol 1987;252:G250-256.

9 Womack WA, Tygart PK, Mailman D, Kvietys PR, Granger DN: Villous motility: Relationship to lymph flow and blood flow in the dog jejunum. Gastroenterology 1988;94:977-983.

10 Womack WA, Mailman D, Kvietys PR, Granger DN: Neurohumoral control of villous motility. Am J Physiol 1988;255:G162-167.

11 Mailman D, Womack WA, Kvietys PR, Granger DN: Villous motility and unstirred water layers in canine intestine. Am J Physiol 1990; 258:G238-G246.

12 Husebye E: The patterns of small bowel motility: Physiology and implications in organic disease and functional disorders. Neurogastroenterol Motil 1999;11:141-161.

13 Kuemmerle JF: Motility disorders of the small intestine: New insights into old problems. $\mathbf{J}$ Clin Gastroenterol 2000;31:276-281.

14 Miftakhov RN, Wingate DL: Biomechanics of small bowel motility. Med Eng Phys 1994;16: 406-415.

15 Miftakhov R, Wingate D: Numerical simulation of the peristaltic reflex of the small bowel. Biorheology 1994;31:309-325.

16 Bertuzzi A, Mancinelli R, Pescatori M, Salinari S: An analysis of the peristaltic reflex. Biol Cybern 1979;35:205-212.

17 Watters DA, Smith AN, Eastwood MA, Anderson KC, Elton RA: Mechanical properties of the rat colon: The effect of age, sex and different conditions of storage. Q J Exp Physiol 1985;70:151-162.
$18 \mathrm{McNeil}$ PL, Ito S: Gastrointestinal cell plasma membrane wounding and resealing in vivo. Gastroenterology 1989;96:1238-1248.

19 Alizadeh H, Weems WA, Castro GA: Longterm influence of enteric infection on jejunal propulsion in guinea pigs. Gastroenterology 1989;97:1461-1468.

20 Weems WA, Weisbrodt NW: Ileal and colonic propulsive behavior: contribution of enteric neural circuits. Am J Physiol 1986;250:G653G659.

21 Mimura T, Emanuel A, Kamm MA: Pathophysiology of diverticular disease. Best Pract Res Clin Gastroenterol 2002;16:563-576.

22 Nakaji S, Danjo K, Munakata A, Sugawara K, MacAuley D, Kernohan G, Baxter D: Comparison of etiology of right-sided diverticula in Japan with that of left-sided diverticula in the West. Int J Colorect Dis 2002; 17:365-373.

23 Murakami H, Iwane S, Munakata A, Nakaji S, Sugawara K, Tsuchida S, Sasaki D: Changes in intraluminal pressure in rat large intestines with aging and effects of dietary fiber. Dig Dis Sci 2001;46:1247-1254.

24 Brodribb AJ, Condon RE, Cowles V, DeCosse $\mathrm{JJ}$ : Effect of dietary fiber on intraluminal pressure and myoelectrical activity of left colon in monkeys. Gastroenterology 1979;77:70-74.

25 Cook IJ, Irvine EJ, Campbell D, Shannon S, Reddy SN, Collins SM: Effect of dietary fiber on symptoms and rectosigmoid motility in patients with irritable bowel syndrome. A controlled, crossover study. Gastroenterology 1990;98:66-72.

26 Smith AN, Drummond E, Eastwood MA: The effect of coarse and fine Canadian Red Spring Wheat and French Soft Wheat bran on colonic motility in patients with diverticular disease. Am J Clin Nutr 1981;34:2460-2463.

27 Simpson J, Scholefield JH, Spiller RC: Pathogenesis of colonic diverticula. Br J Surg 2002; 89:546-554.

28 Eastwood MA, Smith AN, Brydon WG, Pritchard $\mathrm{J}$ : Comparison of bran, ispaghula, and lactulose on colon function in diverticular disease. Gut 1978;19:1144-1147.

29 Friedman HI, Cardell RR Jr: Alterations in the endoplasmic reticulum and Golgi complex of intestinal epithelial cells during fat absorption and after termination of this process: A morphological and morphometric study. Anat Rec 1977; 188:77-101.

30 Tasman-Jones C, Owen RL, Jones AL: Semipurified dietary fiber and small-bowel morphology in rats. Dig Dis Sci 1982;27:519-524.

31 Harding JD, Cairnie AB: Changes in intestinal cell kinetics in the small intestine of lactating mice. Cell Tissue Kinet 1975;8:135-144.

32 Lichtenberger LM, Trier JS: Changes in gastrin levels, food intake and duodenal mucosal growth during lactation. Am J Physiol 1979; 237:E98-E105.

33 Hanson WR, Osborne JW, Sharp JG: Compensation by the residual intestine after intestinal resection in the rat. II. Influence of postoperative time interval. Gastroenterology 1977;72: $701-705$.
34 Williamson RC: Intestinal adaptation. 1. Structural, functional and cytokinetic changes. $\mathrm{N}$ Engl J Med 1978;298:1393-1402.

35 Carr KE, Bullock C, Ryan SS, McAlinden MG, Boyle FC: Radioprotectant effects of atropine on small intestinal villous shape. J Submicrosc Cytol Pathol 1991;23:569-577.

36 Inoue Y, Grant JP, Snyder PJ: Effect of glutamine-supplemented total parenteral nutrition on recovery of the small intestine after starvation atrophy. J Parenter Enteral Nutr 1993;17: 165-170.

37 Marshak RH, Khilnani M, Eliasoph J, Wolf BS: Intestinal edema. Am J Roentgenol Radium Ther Nucl Med 1967;101:379-387.

38 Luckey A, Livingston E, Tache Y: Mechanisms and treatment of postoperative ileus. Arch Surg 2003;138:206-214.

39 Kehlet H, Holte K: Review of postoperative ileus. Am J Surg 2001;182:3S-10S.

40 Granger DN, Barrowman JA: Microcirculation of the alimentary tract. II. Pathophysiology of edema. Gastroenterology 1983;84:1035-1049.

41 Lacy ER: Epithelial restitution in the gastrointestinal tract. J Clin Gastroenterol 1988; 10(suppl 1):72-77.

42 Basson MD: Role of integrins in enterocyte migration. Clin Exp Pharmacol Physiol 1998; 25:280-285.

43 Kolega J: The movement of cell clusters in vitro: Morphology and directionality. J Cell Sci 1981;49:15-32.

44 Dipasquale A: Locomotory activity of epithelial cells in culture. Exp Cell Res 1975;94:191215.

45 Wang N, Naruse K, Stamenovic D, Fredberg JJ, Mijailovich SM, Tolic-Norrelykke IM, Polte T, Mannix R, Ingber DE: Mechanical behavior in living cells consistent with the tensegrity model. Proc Natl Acad Sci USA 2001; 98:7765-7770.

46 Frangos SG, Knox R, Yano Y, Chen E, Di Luozzo G, Chen AH, Sumpio BE: The integrinmediated cyclic strain-induced signaling pathway in vascular endothelial cells. Endothelium 2001;8:1-10.

47 Pugin J: Molecular mechanisms of lung cell activation induced by cyclic stretch. Crit Care Med 2003;31:S200-206.

48 Mobasheri A, Carter SD, Martin-Vasallo P, Shakibaei M: Integrins and stretch activated ion channels; putative components of functional cell surface mechanoreceptors in articular chondrocytes. Cell Biol Int 2002;26:1-18.

49 Iba T, Maitz S, Furbert T, Rosales O, Widmann MD, Spillane B, Shin T, Sonoda T, Sumpio BE: Effect of cyclic stretch on endothelial cells from different vascular beds. Circ Shock 1991;35:193-198

50 Matsuda N, Morita N, Matsuda K, Watanabe $\mathrm{M}$ : Proliferation and differentiation of human osteoblastic cells associated with differential activation of MAP kinases in response to epidermal growth factor, hypoxia, and mechanical stress in vitro. Biochem Biophys Res Commun 1998;249:350-354. 
51 Murnin M, Kumar A, Li GD, Brown M, Sumpio $\mathrm{BE}$, Basson MD: Effects of glutamine isomers on human (Caco-2) intestinal epithelial proliferation, strain-responsiveness and differentiation. J Gastrointest Surg 2000;4:435-442.

52 Ingber DE: Opposing views on tensegrity as a structural framework for understanding cell mechanics. J Appl Physiol 2000;89:16631670.

53 Zhang J, Li W, Sanders MA, Sumpio BE, Panja A, Basson MD: Regulation of the intestinal epithelial response to cyclic strain by extracellular matrix proteins. FASEB J 2003; 17:926-928.

54 Wang DS, Proffit D, Tsao PS: Mechanotransduction of endothelial oxidative stress induced by cyclic strain. Endothelium 2001;8:283-291.

55 Wilson E, Sudhir K, Ives HE: Mechanical strain of rat vascular smooth muscle cells is sensed by specific extracellular matrix/integrin interactions. J Clin Invest 1995;96:23642372.

56 Wang N, Ingber DE: Control of cytoskeletal mechanics by extracellular matrix, cell shape, and mechanical tension. Biophys J 1994;66: 2181-2189.

57 Cooke HJ, Wunderlich J, Christofi FL: 'The force be with you': ATP in gut mechanosensory transduction. News Physiol Sci 2003;18:4349.

58 Slott PA, Liu MH, Tavoloni N: Origin, pattern and mechanism of bile duct proliferation following biliary obstruction in the rat. Gastroenterology 1990;99:466-477.

59 Haussinger D, Kurz AK, Wettstein M, Graf D, Vom Dahl S, Schliess F: Involvement of integrins and $\mathrm{Src}$ in tauroursodeoxycholate-induced and swelling-induced choleresis. Gastroenterology 2003;124:1476-1487.

60 Mennigen R, Kusche J, Leisten L, Erpenbach $\mathrm{K}$ : Diamine oxidase activity and intestinal mucosa integrity: Influence of suture techniques. Agents Actions 1987;20:277-280.

61 Clarke RM: Evidence for both luminal and systemic factors in the control of rat intestinal epithelial replacement. Clin Sci Mol Med 1976;50: 139.

62 Basson MD, Coppola CP: Repetitive deformation and pressure activate small bowel and colonic mucosal tyrosine kinase activity in vivo. Metabolism 2002;51:1525-1527.

63 Feldman EJ, Dowling RH, McNaughton J, Peters TJ: Effects of oral versus intravenous nutrition on intestinal adaptation after small bowel resection in the dog. Gastroenterology 1976;70: 712-719.

64 Levine GM, Deren JJ, Yezdimir E: Small-bowel resection. Oral intake is the stimulus for hyperplasia. Am J Dig Dis 1976;21:542-546.

65 Gleeson $\mathrm{MH}$, Dowling RH, Peters TJ: Biochemical changes in intestinal mucosa after experimental small bowel by-pass in the rat. Clin Sci 1972; 43:743-757

66 Sagor GR, Ghatei MA, Al-Mukhtar MY, Wright NA, Bloom SR: Evidence for a humoral mechanism after small intestinal resection. Exclusion of gastrin but not enteroglucagon. Gastroenterology 1983;84:902-906.
67 Kissmeyer-Nielsen P, Christensen H, Laurberg S: Growth hormone treatment of rats with chronic diverting colostomy. Differential response on proximal functioning and distal atrophic colon. Eur J Endocrinol 1994;130:508514.

68 Delvaux G, Caes F, Willems G: Influence of a diverting colostomy on epithelial cell proliferation in the colon of rats. Eur Surg Res 1983;15: 223-229.

69 Scheppach W, Christl SU, Bartram HP, Richter F, Kasper H: Effects of short-chain fatty acids on the inflamed colonic mucosa. Scand $\mathbf{J}$ Gastroenterol Suppl 1997;222:53-57.

70 Souba WW, Scott TE, Wilmore DW: Intestinal consumption of intravenously administered fuels. J Parenter Enteral Nutr 1985;9:18-22.

71 Page CP: Edgar J. Poth lecture. The surgeon and gut maintenance. Am J Surg 1989;158: 485-490.

72 Perdikis DA, Basson MD: Basal nutrition promotes human intestinal epithelial (Caco-2) proliferation, brush border enzyme activity, and motility. Crit Care Med 1997;25:159-165.

73 Peterson MD, Mooseker MS: Characterization of the enterocyte-like brush border cytoskeleton of the $\mathrm{C} 2 \mathrm{BBe}$ clones of the human intestinal cell line, Caco-2. J Cell Sci 1992;102:581600.

74 Basson MD, Li GD, Hong F, Han O, Sumpio BE: Amplitude-dependent modulation of brush border enzymes and proliferation by cyclic strain in human intestinal Caco-2 monolayers. J Cell Physiol 1996;168:476-488.

75 Han O, Li GD, Sumpio BE, Basson MD: Strain induces Caco-2 intestinal epithelial proliferation and differentiation via PKC and tyrosine kinase signals. Am J Physiol 1998;275:G534G541.

76 Han O, Sumpio BE, Basson MD: Mechanical strain rapidly redistributes tyrosine phosphorylated proteins in human intestinal Caco- 2 cells. Biochem Biophys Res Commun 1998;250: 668-673.

77 Li W, Duzgun A, Sumpio BE, Basson MD: Integrin and FAK-mediated MAPK activation is required for cyclic strain mitogenic effects in Caco-2 cells. Am J Physiol 2001;280:G75G87.

78 Zhang J, Li W, Sumpio BE, Basson MD: Fibronectin blocks p38 and jnk activation by cyclic strain in Caco-2 cells. Biochem Biophys Res Commun 2003;306:746-749.

79 Holund B: Demonstration of fibronectin in normal and acutely inflamed appendix. Histochemistry 1987;86:427-431.

80 Scott DL, Morris CJ, Blake AE, Low-Beer TS, Walton KW: Distribution of fibronectin in the rectal mucosa. J Clin Pathol 1981;34:749-758.

81 Tani T, Tsutamoto Y, Eguchi Y, Araki H, Ebira Y, Ameno H, Fujino M, Oka H, Kodama M: Protease inhibitor reduces loss of tensile strength in rat anastomosis with peritonitis. $\mathrm{J}$ Surg Res 2000;88:135-141.

82 Ito M, Hirata S, Arai S, Takahashi T: T-cell adherence and mucosal injury in ulcerative colitis: Involvement of integrin-fibronectin interaction in situ. J Gastroenterol 1995;30(suppl 8):70-72.
83 Velky TS, Yang JC, Greenburg AG: Plasma fibronectin response to sepsis: Mobilization or synthesis? J Trauma 1984;24:824-829.

84 Verspaget HW, Biemond I, Allaart CF, van Weede H, Weterman IT, Gooszen HG, Pena AS, Lamers CB: Assessment of plasma fibronectin in Crohn's disease. Hepatogastroenterology 1991;38:231-234.

$85 \mathrm{Yu} \mathrm{CF}$, Sanders MA, Basson MD: Human caco-2 motility redistributes FAK and paxillin and activates p38 MAPK in a matrix-dependent manner. Am J Physiol 2000;278:G952G966.

86 Osada T, Watanabe S, Tanaka H, Hirose M, Miyazaki A, Sato N: Effect of mechanical strain on gastric cellular migration and proliferation during mucosal healing: role of Rhodependent and Rac-dependent cytoskeletal reorganisation. Gut 1999;45:508-515.

87 Basson MD, Yu CF, Herden-Kirchoff O, Ellermeier M, Sanders MA, Merrell RC, Sumpio BE: Effects of increased ambient pressure on colon cancer cell adhesion. J Cell Biochem 2000;78:47-61.

88 Thamilselvan VJ, Basson MD: Pressure activates colon cancer cell adhesion by inside-out focal adhesion complex and actin cytoskeletal signaling. Gastroenterology 2004;126:8-18.

89 Gutt CN, Kim ZG, Hollander D, Bruttel T, Lorenz $\mathrm{M}$ : $\mathrm{CO}_{2}$ environment influences the growth of cultured human cancer cells dependent on insufflation pressure. Surg Endosc 2001;15:314-318.

90 Hirokawa M, Miura S, Kishikawa H, Yoshida H, Nakamizo H, Higuchi H, Nakatsumi RC, Suzuki H, Saito H, Ishii H: Loading of mechanical pressure activates mitogen-activated protein kinase and early immediate gene in intestinal epithelial cells. Dig Dis Sci 2001;46:19932003.

91 Kishikawa H, Miura S, Yoshida H, Hirokawa M, Nakamizo H, Higuchi H, Adachi M, Nakatsumi RC, Suzuki H, Saito H, Ishii H: Transmural pressure induces IL-6 secretion by intestinal epithelial cells. Clin Exp Immunol 2002;129: 86-91.

92 Nemeth ZH, Deitch EA, Szabo C, Hasko G: Hyperosmotic stress induces nuclear factor- $\kappa \mathrm{B}$ activation and interleukin- 8 production in human intestinal epithelial cells. Am J Pathol 2002;161:987-996.

93 Kim M, Javed NH, Yu JG, Christofi F, Cooke HJ: Mechanical stimulation activates Galphaq signaling pathways and 5-hydroxytryptamine release from human carcinoid BON cells. J Clin Invest 2001;108:1051-1059.

94 Kirchgessner AL, Tamir H, Gershon MD: Identification and stimulation by serotonin of intrinsic sensory neurons of the submucosal plexus of the guinea pig gut: Activity-induced expression of Fos immunoreactivity. J Neurosci 1992; 12:235-248.

95 Kirchgessner AL, Liu MT, Gershon MD: In situ identification and visualization of neurons that mediate enteric and enteropancreatic reflexes. J Comp Neurol 1996;371:270-286. 